\title{
Crypto Assets Regulation in the UK: An Assessment of the Regulatory Effectiveness and Consistency \\ Huang, Sherena
}

\section{Journal of Financial Regulation and Compliance}

\author{
DOI: \\ 10.1108/JFRC-06-2020-0062
}

Published: 14/07/2021

Peer reviewed version

Cyswllt i'r cyhoeddiad / Link to publication

Dyfyniad o'r fersiwn a gyhoeddwyd / Citation for published version (APA):

Huang, S. (2021). Crypto Assets Regulation in the UK: An Assessment of the Regulatory

Effectiveness and Consistency. Journal of Financial Regulation and Compliance, 29(3), 336-351. https://doi.org/10.1108/JFRC-06-2020-0062

\footnotetext{
Hawliau Cyffredinol / General rights

Copyright and moral rights for the publications made accessible in the public portal are retained by the authors and/or other copyright owners and it is a condition of accessing publications that users recognise and abide by the legal requirements associated with these rights.

- Users may download and print one copy of any publication from the public portal for the purpose of private study or research.

- You may not further distribute the material or use it for any profit-making activity or commercial gain

- You may freely distribute the URL identifying the publication in the public portal?
}

Take down policy

If you believe that this document breaches copyright please contact us providing details, and we will remove access to the work immediately and investigate your claim. 
Crypto Assets Regulation in the UK: An Assessment of the Regulatory Effectiveness and Consistency

\begin{tabular}{|r|l|}
\hline Journal: & Journal of Financial Regulation and Compliance \\
\hline Manuscript ID & JFRC-06-2020-0062.R3 \\
\hline Manuscript Type: & Original Article \\
\hline Keywords: & Bitcoin, Cryptocurrency, Crypto-assets regulation, FinTech \\
\hline \multicolumn{2}{l}{} \\
\end{tabular}

SCHOLARONE ${ }^{m}$

Manuscripts 
1 Crypto-assets Regulation in the UK: An Assessment of the Regulatory

2 Effectiveness and Consistency

\author{
3 Abstract \\ 4 \\ 5 \\ 6 \\ Purpose

5 \\ The UK authority published its first regulatory guidance on crypto-assets in July 2019. \\ This paper aims to critically evaluate the effectiveness of the crypto-asset regulation in \\ the UK and the consistency of the existing regulatory scheme.

\section{Design/methodology/approach} \\ This paper adopts comparative methods to carry out the analysis. The paper begins by \\ elaborating the development of crypto-assets alongside the financial innovation in the \\ world and pinpointing the core Acts and Regulations applied to crypto-assets in the \\ UK. The paper also discusses a court case in the EU to highlight an argument among \\ legal professions concerning crypto-assets classification.
}

\title{
Finding
}

Through carefully analysing relevant primary and secondary legislation of the UK and $\mathrm{EU}$, this paper identifies some unclarified issues in the regulatory framework and discovers three flaws in the regulatory system. The paper concludes that the effectiveness of the current regulatory scheme is poor and room for improvement exists.

\section{Originality/value}

The paper provides the first review and a thorough analysis of the Laws and Acts applied to the crypto-asset regulation in the UK. It also calls on a simpler and clearer regulatory scheme from the perspectives of market participants and consumers. The discovered issues in the crypto-asset regulation in the UK may urge authorities to improve the existing regulatory frameworks and legal provisions.

Keywords: FinTech, Crypto-assets regulation, Bitcoin, Cryptocurrency 


\section{Introduction}

28 The Financial Conduct Authority (FCA) finalised a framework in July 2019 to regulate

29 business activities of crypto-assets (FCA, 2019b). Crypto-assets were created as 'a purely

30 peer-to-peer version of electronic cash' by Nakamoto in 2008 (Nakamoto, 2008, p.1). Crypto-

31 assets use Blockchain — 'a shared, immutable record of peer-to-peer transactions built from

32 linked transaction blocks and stored in a digital ledger' (Holloway, 2017, pp.3-4), which is

33 one application of the Distributed Ledger Technology (DLT)—distributed network

34 technology (Reyes, 2017, p.8).

35 Crypto-assets carry multifaceted characteristics consisting of virtual property and financial 36 products and have been adopted in payment transactions, financial instruments, investments 37 and corporate coupons (The World Bank, 2017; HM Treasury et al., 2018; FCA, 2019b).

38 Although the technology comes with enhanced efficiency and security (Holloway, 2017), it 39 offers an anonymous network for value transactions without financial intermediaries, which 40 has caused concerns over financial crimes, such as money laundering (Albrecht et al., 2019;

41 Blundell-Wignall, 2014; Brown, 2016; Irwin and Turner, 2018). A trade-off exists in 42 policymaking between regulation and financial inclusion: strict regulation of crypto-assets 43 will impede technology innovation and investments; non-intervention may expose investors 44 and consumers to risks. Is the existing regulatory framework effective and consistent and 45 what is its impact on market participants? This paper intends to examine the consistency and 46 effectiveness of existing regulatory regimes in the United Kingdom (UK) and identifies 47 potential issues, accordingly.

48 Crypto-assets have been involved in financial misconduct in some countries. The knockdown

49 of a dark web-Silk Road in the United States (US) in 2013 (US v Matthew Jones, 2014) and 50 the arrest of two former Federal agents in 2015 (US v Carl Mark Force IV, 2015) marked the 51 first combat of crypto-assets crime in the world. More than \$1.5 million US Dollar worth of 
52 money was involved and the illicit earnings were laundered on an international crypto-assets

53 platform-BTC-e (Magnuson, 2020, p.95). The BTC-e was ordered shut down and the

54 owner, Alexander Vinnik (Russian), was arrested in Greece in July 2017 (NDC-Department 55 of Justice, 2017) and was remanded in custody in Greece (BBC News, 2019) at the time of 56 writing. Also in 2017, a cross-border and large-scale money laundering group was shut down 57 by the European Union Agency for Law Enforcement Cooperation (Europol), 23 people were 58 arrested. The involved amount was around $€ 2.5$ million, and the criminals were from Spain, 59 Colombia and Venezuela (Europol, 2019a). In earlier 2019, the Europol, Canada and the 60 United States of America (US) Joined Forces targeted the users of controlled products on 61 dark web marketplaces, 61 people were arrested, and 50 illicit dark web accounts were 62 closed, the involved amount was over $€ 6.2$ million (Europol, 2019b). The soaring popularity 63 and cross-border use of crypto-assets used for internationally organised crimes or potential 64 illegal purposes stress why competent authorities around the world must deliberate on the 65 establishment of regulatory schemes.

66 As of June 2020, there were over 5,537 crypto-assets $^{[1]}$ and more than 265 crypto-assets 67 exchanges ${ }^{[2]}$ available online. The number of crypto-assets doubled from July 2019. ${ }^{[3]}$ 68 Bitcoins, the original and by far the most popular crypto-assets launched in January 2008 69 (Nakamoto, 2008) hold the majority of the global market shares (CoinMarketCap, 2020) and 70 have been used as intermediaries for value transactions worldwide. Walch (2015, pp.40-41) 71 believes that the DLT makes value transactions more efficient, economical, secure and 72 transparent and explains that 'open-source software is less vulnerable and more resilient than 73 proprietary software, because the development of the software is transparent, and since more 74 eyes are looking for bugs, more bugs will be noticed and fixed'. Authorities are also 75 following up with the technology development (Arner et al., 2017), such as Regulatory 
76 Technology (FCA, 2017) that aims to enhance the efficiency of market oversight, reporting

77 and compliance.

78 The FCA set forth a relevant regulatory framework of crypto-assets in 2019 under the

79 Financial Services and Markets Act 2000 (Regulated Activities) Order 2001 SI 2001/544

80 (RAO 2001) and the Perimeter Guidance Manual 2019 (PERG 2019) and categorises crypto81 assets into four types: security tokens, e-money tokens, exchange tokens and utility tokens.

82 Of which, the security token and e-money token fall within the regulatory perimeters of the

83 FCA corresponding to specified investment/financial instruments and e-money, respectively.

84 However, regulatory flaws exist. Article 76 of the RAO 2001 regarding shares of specified

85 investments contains convoluted phrases, which may perplex market participants; the PERG

862019 allows exemptions for the European Economic Area (EEA) firms operating in the UK

87 and through the internet under the single market system, however, EEA licensed crypto-

88 assets may fall outside the regulatory perimeters of the FCA.

89 For instance, the European Banking Authority (EBA) categorises crypto-assets into three

90 types: investment tokens, exchange/payment tokens and utility tokens (EBA, 2019, pp.6-7)

91 and Bitcoin-like tokens that fall outside the regulatory perimeters of the FCA (FCA, 2019b)

92 are grouped into exchange/payment tokens and are able to apply for licences in the EU (EBA, $932019, \mathrm{p} 22)$.

94 In addition, the classification of crypto-assets in the UK presents some flaws. A crypto-asset 95 may fit in multiple categories, for instance, utility tokens can be identified as investment 96 tokens, exchange tokens or e-money tokens. The FCA states that falling into the regulatory 97 perimeters does not determine the regulatory status, while crypto-assets may move from one 98 category to another during their business cycle. Therefore, the FCA will identify the 99 regulatory status of crypto-assets on a case by case basis (FCA, 2019b). This complicates the 100 regulatory process for both market participants and the regulator and indirectly increases the 
101 cost of financial technology (FinTech) firms. This regulatory regime is inflexible and

102 inefficient in response to the rapid technology innovation in the financial sector. The

103 regulatory complexity may also cause managerial uncertainty at UK firms; cumulative

104 managerial uncertainty can further transfer to consumers through the markets and incur risks.

105 This paper intends to address the flaws in current regulatory regimes in the UK and draw

106 attention to potential risks.

\section{Background}

108 Definition of crypto-assets and relevant literature

109 Crypto-assets, as one of the notable outcomes of FinTech-built on DLT and Blockchain,

110 offer a new approach for value transactions with enhanced privacy and efficiency. These

111 crypto-assets operate as an intermediary of exchange at a person-to-person level enabling

112 direct payments between individuals (Badev and Chen, 2014, p.5; Walch, 2015, p.6; The

113 World Bank, 2017, p.IV; Houben and Snyers, 2018, p.15; Dryall, 2018, pp.15, 158-161).

114 Crypto-assets transactions are anonymous or semi-anonymous and processed on peer-to-peer

115 networks using encrypted keys that are generated randomly and held by transaction parties

116 only (Li et al., 2019).

117 The DLT refers broadly to a distributed network technology that:

(1) [E]nables users to upload programs and to leave the programs to self-execute; (2) program; (3) is distributed; (4) uses public key cryptography for authentication; and (5) uses a consensus mechanism to ensure that the network maintains the technology'(Reyes, 2017, p.8).

123 And 
[B]lockchain is a shared, immutable record of peer-to-peer transactions built from linked transaction blocks and stored in a digital ledger. ... Blockchain is alleged to be: (1)

Transparency and Privacy; (2) Security and Reliability; (3) Trust and Integrity

(Holloway, 2017, pp.3-4).

The technology establishes point-to-point or peer-to-peer networks enabling permissionless and anonymous transactions, which causes issues in identifying the rights and liabilities. The initial idea of peer-to-peer networks was to share music files freely and anonymously within users on a music platform, 'Napster', using 'BitTorrent'(Stern, 2000, p.4). Napster was charged with infringement of copyright for indirectly distributing music files without authorisation and was ordered shut down in 2001. Although Napster did not directly breach copyright as the peer-to-peer network did not hold or store music (A\&M Records, Inc. $v$. Napster, 2001), the technology was banned (Brown, 2016, pp.330-331). The idea of peer-topeer sharing was well received, while the ban of Napster was criticised by online users and legal professions for undermining creation in the music industry (Shih and $\mathrm{Ku}, 2002$, p.263; Landes and Lichtman, 2003, p.119).

Similar to Napster, the peer-to-peer network allows anonymous crypto-asset transactions. The anonymity together with the permission-less network has opened a window for financial misconduct (Murray, 2019, pp.438-452). This has challenged the regulatory capacity of the financial sector (Buocz et al., 2019; Vandezande and KU Leuven Centre for IT \& IP Law, 2018; The World Bank, 2017; Dryall, 2018).

\section{The creator of Bitcoins, Nakamoto, states that}

[P]urely peer-to-peer version of electronic cash would allow online payments to be sent directly from one party to another without going through a financial institution. ... We propose a solution to the double-spending problem using a peer-to-peer network. The network timestamps transactions by hashing them into an ongoing chain of hash-based proof-of-work, forming a record that cannot be changed without redoing the proof-ofwork. ... As long as a majority of CPU power is controlled by nodes that are not 
151 cooperating to attack the network, they'll generate the longest chain and outpace attackers 152 (Nakamoto, 2008, p.1).

153 The Organisation for Economic Co-operation and Development (OECD) emphasises the

154 potential issues of crypto-assets in consumer protection, including value volatilities and 155 business shutdown (Blundell-Wignall 2014, p.7); the International Monetary Fund (IMF)

156 discusses the risks of crypto-assets and urges authorities to introduce relevant regulations to 157 ensure market integrity (IMF, 2018); a joint publication of Her Majesty’s Treasury (HMT), 158 the FCA and the Bank of England (BoE) discusses the features of crypto-assets and provides 159 the definition (HM Treasury et al., 2018).

160 Academic studies have investigated some crypto-assets related issues, such as user privacy 161 and cybersecurity (Li et al., 2019; Ng and Kwok, 2017; Buocz et al., 2019), money

162 laundering and terrorism financing (Vovchenko et al., 2017; Teichmann, 2018; Turner and 163 Irwin, 2018; Albrecht et al., 2019; Irwin and Dawson, 2019), however, discussions on the 164 Laws and Regulations of crypto-assets in the UK are sparse. There are institutional studies 165 and books providing overviews of the regulations of crypto-assets around the world. For 166 instance, Norton Rose Fulbright (2015) gives an introduction of the global legal framework 167 of crypto-assets in 2015; Arner and others (2017) emphasise the importance of digital 168 innovation in regulation and suggest sequenced reforms; the Law Library of Congress (2018) 169 studies the regulation of crypto-assets in multiple countries in 2018; The Cambridge Centre 170 for Alternative Finance provides an overview of crypto-assets development around the world 171 in 2019 (Blandin et al., 2019); and Dean and others (2019) list the associated issues of 172 crypto-assets with the financial systems; Hughes (2020) reviews the definitions and functions 173 of crypto-assets and global responses. These studies only summarise crypto-assets regulations 174 in different countries. In addition, official working papers of the UK focus on the 
175 interpretations of the aims, scope and process of the regulatory frameworks (HM Treasury et

176 al., 2018; FCA, 2019a), whilst the evaluations of their regulatory schemes are absent.

\section{Regulatory Framework of Crypto-assets in the UK}

178 The Legal Basis

179 The FCA published a consultation paper in January 2019 to collect feedback on its initial

180 regulatory framework (FCA, 2019a). Within six months, the FCA received feedback from 92

181 parties of 10 sectors, including large banks, FinTech firms, crypto-assets issuers, exchanges,

182 and custody service providers. Based on the feedback, the FCA finalised the guidance of

183 crypto-assets regulation in July 2019 by virtue of a document titled 'Guidance on Crypto-

184 assets Feedback and Final Guidance to CP 19/3'. The objective of the final guidance is to

185 provide clarification on crypto-assets falling within or outside the regulatory remits of the

186 FCA and to set forth the obligations on market participants (FCA, 2019b).

187 The fundamental Acts and Regulations applied in the guidance paper are the Financial

188 Services and Markets Act (FSMA) 2000 c.8, the PERG 2019, the RAO 2001, the Electronic

189 Money Regulations (EMR) 2011 SI 2011/99 (EMR 2011), the EU Markets in Financial

190 Instruments Directive II (MiFID II) (Council Directive 2014/65/EU, 2014), as well as the

191 FCA Handbook and the Prudential Regulation Authority (PRA) Rulebook.

192 The FCA categorises crypto-assets into four types of tokens: security tokens, e-money tokens,

193 exchange tokens and utility tokens. Security tokens and e-money tokens are grouped in the

194 category of regulated tokens, otherwise unregulated tokens. Generally, security tokens refer

195 to crypto-assets presenting similar characteristics as traditional shares or debentures; e-money

196 tokens are the crypto-assets that fall into the definition of e-money under the EMR 2011;

197 exchange tokens refer to crypto-assets used as a means of remittances, such as Bitcoins; 
198 utility tokens are crypto-assets that allow holders to have access to the current or prospective

199 product or services with agreed conditions (FCA, 2019b, p.30).

200 Identifying the regulatory status of crypto-assets follows three steps. First, market

201 participants shall identify if they are carrying on activities by way of business in the UK

202 under the PERG 2019 and Sections 22, 418 and 419 of the FSMA 2000. In addition,

203 Schedule 2 of the FSMA 2000 pinpoints that By Way of Business in the UK refers to

204 business or business-like activities in the UK including domestic and overseas registered

205 venues. However, this excludes individuals (excluding self-employed or freelancers) and

206 non-profit institutions that carry on irregular commercial activities (FCA, 2019c, section.2.3).

207 The second step requests market participants to identify if their crypto-assets fall within the

208 definition of specified investments under Part 3 of the RAO 2001. Some financial instruments

209 defined under the MiFID II are recognised as certain types of investments and mapped to the

210 RAO 2001(FCA, 2019b, p.29).

211 The third and final step is to identify whether crypto-assets fall within the definition of e-

212 money under the EMR 2011 (FCA, 2019b, p.30) if crypto-assets fall outside the categories of

213 specified investments. Crypto-assets products falling outside the definitions of both specified

214 investments and e-money are categorised as unregulated tokens.

\section{Regulated Crypto Tokens}

216 Crypto tokens that show clear ownership rights or contractual rights are classified as

217 regulated tokens in the UK (FCA, 2019b, pp.14 and 34-39). Token holders may participate in

218 multiple crypto-assets activities, only tokens that fall within the definition of security tokens

219 and e-money tokens are regulated by the FCA (FCA, 2019b, pp.40-48). 
221 The FCA classifies security tokens following the definition of 'Specified Investments' under

222 the RAO 2001(FCA, 2019b, p.40). The classification focuses on the legal titles of crypto-

223 assets investments and whether the legal titles are negotiable and transferable ${ }^{[4]}$ on capital

224 markets. Specified investments of the kind include Shares, Debentures, Warrants and Units in

225 Collective Investment Schemes.

226 Shares of crypto-assets are defined under Article 76 of the RAO 2001. Crypto-assets shares

227 shall be registered under the names of a natural/legal person/persons, who can provide clear

228 identity information of the ownership. The shareholders can be any person in the UK or

229 overseas constituted under the law of the country. Crypto-assets present similar properties as

230 shares of specified investments and are negotiable and transferable on the capital markets are

231 considered as security tokens in accordance with business operation, corporate law and

232 MiFID; the operation of a company can be used as a reference but not determinants (FCA,

233 2019b, p.41).

234 Crypto-asset debentures are defined under Article 77 of the RAO 2001 —'instruments

235 creating or acknowledging indebtedness'. This category refers to debentures, debenture stock,

236 loan stock, bonds, certificates of deposit and any other instrument creating or acknowledging

237 indebtedness. This does not include borrowed money for defraying or paying goods or

238 services and heritable security which might be payable using crypto-assets, and it does not

239 include government and public securities. The certificates of deposit are unlikely to be

240 recognised as crypto-assets and are not yet treated as deposits. Negotiable and transferable

241 indebtedness crypto-assets could be treated as security tokens under MiFID II only if the

242 legal titles of token holders are clear or identifiable and have the rights to trade on capital

243 markets (FCA, 2019b, pp.42-43).

244 Crypto-assets acting as warrants follow the definition "Warrants" under Article 79 of the

245 RAO 2001 - 'investments giving entitlements to investments'. Warrants give the rights to 
246 crypto-assets holders to access specified investments, including token-like shares and

247 debentures under Article 76 and 77 of the RAO 2001. Warrants refer to the rights that the

248 token issuer grants token holders to participate in new specified investments directly.

249 Units in Collective Investment Schemes refer to pooled investments including internet-based

250 crowdfunds. Units in Collective Investment Schemes define that investors gaining benefit

251 from the rising income/profit of specified investments based on the proportions of their token

252 shares under Article 80 and 81 of the RAO 2001. The pooled investments refer to one

253 specified investment at a time, investing in multiple specified investments is treated as

254 separate specified investments, even if the investments are operated by the same issuer.

255 However, whether collective token investments fall within the regulatory perimeters of the

256 FCA depends on the agreements or prospectus of the investments, while collective

257 investments involving exchange tokens or utility tokens also fall outside the regulatory

258 perimeters of the FCA (FCA, 2019b, p.44).

E-money Tokens

260 The FCA defines e-money tokens under the EMR 2011 and Article 9b of the RAO

261 2001(FCA, 2019b, p.40). Authorised e-money must be a representative equivalent to the

262 value of users' funds and widely accepted in society (Electronic Money Regulations 2011, SI

$2632011 / 99$, regs. 2 and 3). E-money token issuers can only be third parties in providing

264 transaction services with stabilised rates against fiat money and comply with capital

265 requirements, recordkeeping and money laundering regulation. E-money tokens issued by

266 credit institutions, credit unions and municipal banks for the purpose of debt securities, shall

267 meet a minimal value of redemption of $£ 100,000$ or equivalent value of other currency and

268 shall have an office situated in the UK (Electronic Money Regulations 2011, SI 2011/99, 269 reg.6). 
270 The FCA will identify e-money tokens on a case by case basis. There are possibilities of not

271 being recognised as e-money tokens even crypto-assets falling within the definition of e-

272 money under the EMR 2011 and meet the abovementioned criteria (FCA, 2019b, p.45).

\section{Unregulated Crypto Tokens}

274 The FCA classifies exchange tokens and utility tokens as unregulated tokens (FCA, 2019b,

275 pp.34-36). Unregulated tokens are mainly anonymous and can be transferred directly among

276 users or through crypto-assets service providers. Bitcoins and bitcoin-like crypto-assets are

277 unregulated tokens. Although these tokens fall outside the regulatory perimeters of the FCA,

278 they shall comply with the Fifth Anti-Money Laundering Directive (Council Directive (EU)

279 2018/843, 2018) (AMLD5) of the EU and the Money Laundering and Terrorist Financing

280 (Amendment) Regulations 2019, SI 2019/1511 (MLR 2019) of the UK.

\section{Exchange Tokens}

282 Exchange tokens refer to crypto-assets used for payment transactions or trading on crypto-

283 asset exchanges or stored on custody wallets. The FCA denotes that exchange tokens do not

284 need existing regulatory permissions as there are regulatory rules applying to unregulated

285 crypto-assets. These rules include the Principles for Business (PRIN) 2020 for commercial

286 conduct and the Senior Managers and Certification Regime (SMCR) 2019 for individual

287 conduct, as well as the Banking: Conduct of Business sourcebook (BCOBS) 2020 for banks

288 and financial firms. These rules are applicable to insurers and other FCA regulated firms with

289 activities under the definition of 'SMCR financial activities' including regulated activities

290 and activities in connection with a regulated activity no matter when the connection takes

291 place. 
292 The FCA has recognised the incremental use of exchange tokens and the DLT. However, 293 some characteristics of exchange tokens made them fall outside the regulatory perimeters of

294 the FCA. For instance, anonymity and value volatility. Thus, firms using crypto-assets to

295 facilitate regulated payments must have the correct permission and must follow the relevant

296 Laws and Regulations. This includes, but is not limited to, the Payment Services Regulations 297 2017, SI 2017/752 (PSR 2017), and from 1 August 2019, PRIN 2020 and BCOBS 2020.

298 Certain activities of exchange tokens are regulated under the MLR 2019 implementing of the 299 AMLD5.

$300 \quad$ Utility Tokens

301 Utility tokens refer to crypto-assets acting like 'a current or prospective product or service 302 and often grant rights similar to pre-payment vouchers' (FCA, 2019b, p.36). Utility token 303 owners can be anonymous and trade or exchange their tokens on secondary markets and use 304 their tokens for speculative investment purposes. Utility tokens have a wider range of 305 characteristics that are similar to all other three token classes. Therefore, further clarification 306 of the regulatory perimeters of utility tokens is needed.

\section{Methodology}

308 FinTech blends the subjects of technology and finance, and it becomes more complex when 309 business activity and market regulation engage. To reflect the interdisciplinary nature, this

310 paper employs a comparative legal analysis to estimate the effectiveness of current regulatory 311 frameworks of crypto-assets in the UK.

312 The comparative legal analysis can be used in interdisciplinary subjects (Legrand, 1996) and

313 multi-markets research (Siems and Deakin, 2010). It allows the discussion of 'micro-legal 314 questions' - a specific legal problem, such as a specific provision of a statute or code, or a 
315 specific case or line of cases (Siems, 2008), and assists to identify if 'the subdivisions of a

316 legal concept or field are in a logical, systematic, succinct, and complete way'(Van Hoecke,

317 2016, p.16).

318 FinTech has developed internationally within a short period. Relevant laws and regulations of

319 crypto-assets in most countries are still at their initial phases. Regulatory challenges seem

320 inevitable given the interdisciplinary nature of FinTech, such as balancing financial

321 innovation of crypto-assets and consumer protection (Baer and Pavel, 1988; Yeoh, 2017),

322 whereas evaluation of their regulatory frameworks has lagged behind.

323 Adopting a comparative legal analysis, this paper works up a new perspective on the

324 challenges in financial regulation in the UK and attempts to encourage interdisciplinary

325 discussions on the effectiveness of crypto-assets regulation-if the established regulatory

326 framework is logical, simple to understand and clear to comply with and if it serves the

327 mission of the regulator, the FCA, that is to 'enhancing trust in markets, improving how

328 markets operate, delivering benefits through a common approach to regulation, and working

329 to prevent harm from occurring' (FCA, 2017).

330 The comparative law is, therefore, not just another positivist approach that merely concerned

331 with the rules of a legal system. It is unravelling the use of the law in an interdisciplinary

332 subject and enhances the originality of this paper. A thorough discussion on potential issues

333 of crypto-assets regulation in the UK may assist in decision-making and multi-dimensional

334 improvements.

335 Analysis of Crypto-asset Regulation in the UK

336 Concerns over Crypto-assets Classification

337 A clear classification of crypto-assets helps market participants and legal professions to

338 identify the regulatory status of crypto-assets. A German court case taking place in 2018 
339 could be an example to see how crypto-asset classification could affect prosecution

340 proceedings. The court case between a Bitcoin service provider and the public prosecutor's

341 office of Berlin ("Citizen Service Berlin - Brandenburg - Criminality of trade in bitcoins",

$3422019)^{[5]}$ revealed an issue in identifying the regulatory position of Bitcoins among legal

343 professions - whether Bitcoins are 'financial instruments' (The Law Library of Congress,

344 2018). The lawsuit was on the ground that Bitcoins were financial instruments according to

345 the Federal Financial Supervisory Authority of Germany (BaFin) (2017), therefore the

346 service provider shall apply for a licence to provide banking services and was liable to carry

347 out due diligence measures. However, the court opinion was opposite and adjudicated that

348 Bitcoins were not financial instruments ("Banking Act (KWG)", 2014, s.1(11) (f)) as

349 Bitcoins were neither legal tender nor units of accounts (Act on the Prudential Supervision of

350 Payment Services (Payment Services Supervision Act) 2009, ss.(1a)(1)(5) and (1a)(3)). Both

351 the public prosecutor's office and the court referred to Section 1(11) of the Banking Act 2014,

352 Germany. The dispute was caused by whether Bitcoins were 'Financial Instruments' or

353 'Payment Instruments'.

354 The BaFin defines crypto-assets as financial instruments under the Banking Act 2014

355 regardless of the technology applied (BaFin, 2017). Bitcoin-like crypto-assets are recognised

356 as financial instruments because they are 'comparable to foreign exchange; value units which

357 function as private means of payment in barter transactions that is used as means of

358 payment'(BaFin, 2017). However, the Banking Act 2014 excludes payment instruments from

359 the definition of financial instruments under the German Payment Services Supervision Act

3602009 (Act on the Prudential Supervision of Payment Services (Payment Services Supervision

361 Act) 2009, ss. (1a)(1)(5) and (1a)(3)). Since crypto-assets 'do not represent any claims on an

362 issuer, as in their case there is no issuer' (BaFin, 2017), therefore they are not recognised as 363 payment instruments in Germany, thus, associated service providers do not require banking 
364 licences. The conflict over the German court case lays bare the fact that an unclear

365 classification of crypto-assets could lead to misunderstanding, while similar issues may also

366 take place in the UK as the FCA's classification is even more complicated.

367 The FCA defines security and e-money tokens as regulated tokens, unregulated tokens

368 otherwise (FCA, 2019b, p.34). This classification seems simple, whereas it is practically

369 more complicated than it looks. For example, the FCA states that identifying the regulatory

370 status of crypto-assets (both regulated and unregulated) is on a case by case basis; one or

371 more factors that make a token falling within or outside the regulatory perimeter are not

372 determinative; while crypto-asset may move between the regulatory categories during their

373 existence. The FCA also requires firms to identify relevant permissions themselves and

374 consult independent advice (FCA, 2019b, p.32).

375 This ambiguous classification reflects the policy indecision about crypto-asset regulation: on

376 the one hand, the FCA intends to encourage financial innovation and investments, which

377 allows unregulated tokens to operate in the UK (FCA, 2019b, p.51); on the other hand, the

378 regulator must ensure consumer protection. This implies policy uncertainty on token

379 businesses. For instance, the current regulatory perimeters categorise products that reference

380 crypto-assets as financial instruments under MiFID II as regulated tokens, including

381 derivative instruments (FCA, 2019b, p.45). However, some unregulated tokens that possess

382 properties of securities or derivatives are also financial instruments under MiFID II, such as

383 BitCoins. This ambiguity may incur risks, especially to uninformed consumers. The FCA

384 recognises this issue (FCA, 2019b, pp.40 and 45) and further introduced a ban in October

3852020 on the marketing, distribution and sale of derivatives and exchange traded notes (ETNs)

386 that reference crypto-assets to retail consumers. The rule applies to both UK and EEA MiFID

387 investment firms and comes into force on 6 January 2021 (FCA, 2020). 
388 In addition, the FCA's guideline is inconclusive and costly, especially to market participants.

389 For instance, identifying the regulatory status of crypto-assets on a case by case basis implies

390 a slow licensing process and requires more specialists. This implies extra cost to firms

391 including time and financial cost as well as opportunity cost: a slow process means firms

392 need to wait longer to launch/operate their businesses and pay more on bank loans interests if

393 they borrowed some; business opportunities may slip away during the time of waiting for

394 permission. Meanwhile, a slow process can lead to a backlog of business registrations and

395 delays in an Initial Coin Offering (ICO); investments may go to another country, which has a

396 simpler and faster-licensing process. Additionally, the indeterminate official guidelines will

397 puzzle market participants since falling within the regulatory perimeters does not mean

398 business permission; third party specialists may also hold different viewpoints from one to

399 another due to the unclear classification. The unclear classification may also offer room for

400 financial misconduct and cause conflicts in the regulatory process and legal proceedings.

401 In sum, the current regulatory framework requires further clarification. The abovementioned

402 regulatory issues may become more prominent when the number of market participants

403 increases. The FCA has admitted that there are some 'inherent structural differences'

404 amongst securities markets (FCA, 2019b, p.16) and 'believes' that the final guidance for

405 security tokens is sufficient to market participants and will continuously monitor the

406 developments in the unclarified areas while the market is maturing (FCA, 2019b, p.23).

\section{Regulatory Flaws}

408 In addition to the concerns over crypto-asset classifications, this paper discovers some flaws

409 in the regulatory system. These flaws relate to the core provisions of crypto-assets regulation.

\section{A Regulatory Flaw in Specified Investments}

411 The first flaw exists in Article 76 of the RAO 2001 — shares of specified investments. 
412

413

414

415

416

417

418

419

420

421

422

423

424

425

426

427

428

429

430

431

432

433

434

435

436

437

438

439

440

76. - (1) Shares or stock in the share capital of-

(a) any body corporate (wherever incorporated), and

(b) any unincorporated body constituted under the law of a country or territory outside the United Kingdom.

(2) Paragraph (1) includes-

(b) any transferable shares in a body incorporated under the law of, or any part of, the United Kingdom relating to industrial and provident societies or credit unions, or in a body constituted under the law of another EEA State for purposes equivalent to those of such a body.

(3) But subject to paragraph (2) there are excluded from paragraph (1) shares or stock in the share capital of-

(b) a building society incorporated under the law of, or any part of, the United Kingdom;

(c) a body incorporated under the law of, or any part of, the United Kingdom relating to industrial and provident societies or credit unions;

This Article seems mutually exclusive. Paragraph (1) states that this regulation applies to both incorporated and unincorporated bodies operating in the UK wherever registered.

Specifically, Paragraph (2)(b) includes transferable shares of industrial and provident societies or credit unions, or in a body constituted under the law of another EEA State in Paragraph (1), whereas Paragraph (3) excludes shares of those from Paragraph (1) subject to Paragraph (2).

The term 'transferable' in Paragraph (2)(b) refers to shares that can be freely transferred to any person and at any time in accordance with the issuing company's articles of association (Companies Act 2006 c.46, s.544). Thus, transferable shares, as a part of companies' capital shares, are included in Paragraph (1) under Paragraph (2)(b) but excluded from Paragraph (1) under Paragraph (3)(c) and (d). Therefore, the application of this Article depends on interpretations of legal professions, which sometimes their opinions may differ between one another; speculators may use this to game the system. The RAO 2001 has been updated 
441 regularly between 2001 and 2021, but this has not yet drawn attention to the legislatures of 442 the UK.

443 The mutually exclusive provision will perplex market participants: crypto-assets issued by 444 industrial and provident societies or credit unions, or in a body constituted under the law of 445 another EEA State can be classified as both regulated tokens (specified investments) and 446 unregulated tokens (non-specified investments) under Articles 76(2)(b) and 76 (3)(c)(d) of 447 the RAO 2001, respectively.

448 The regulatory conflict implies policy uncertainty and exposes consumers to risks. It

449 heightens the cost of identifying relevant compliance measures; misapprehension will affect 450 business activities, such as financial promotion, which may further misguide consumers and 451 induce unnecessary regulatory penalties. Therefore, authorities may consider clarifying the 452 Article, accordingly.

453 Regulatory Flaws under the Single Market System

454 The second flaw presents in the PERG 2019 in terms of e-commerce from the EEA.

455 According to the PERG 2019 (section 2.4), a firm registered and established a business venue 456 in the UK shall comply with the Carrying on Regulated Activities by Way of Business

457 wherever registered including overseas persons (PERG, 2019, section 2.4.6). However, 458 overseas persons (PERG, 2019, section 2.9.15G) and e-commerce (except insurance 459 businesses) from the EEA member states are exceptional to the PERG requirement under the 460 single market system (European Commission, n.d.).

(1) In accordance with article 3(2) of the E-Commerce Directive, all requirements on 462 463 persons providing electronic commerce activities into the United Kingdom from the EEA are lifted, where these fall within the co-ordinated field and would restrict the freedom of such a firm to provide services. ... (2) The Regulated Activities Order was amended by the Financial Services and Markets Act 2000 (Regulated Activities) (Amendment) 
466

467

468

469

470

471

472

473

474

475

476

477

478

479

480

481

482

483

484

485

486

487

488

489

490

(Electronic Commerce Directive) Order 2002 (SI 2002/2157). This Order creates a general exclusion from regulated activities (except for the regulated activities of effecting or carrying out contracts of insurance). Where activities consist of electronic commerce activities, an incoming ECA provider will not require authorisation for such activities in the United Kingdom.

The general exclusion may function well if the regulatory requirement of crypto-assets across the EEA countries is harmonised. For example, Bitcoin-like products that are unregulated in the UK can obtain a licence in some EEA countries and then operate in the UK through the internet.

In addition to business authorisation, the disparate regulatory regimes of crypto-assets within the EU (Brophy, 2019) and the single market system may cause another regulatory issue, which is the third flaw this paper has diagnosed. Some EU countries, such as Germany and Malta, have established regulatory frameworks for crypto-assets businesses including Bitcoin-like products (The Virtual Financial Assets Act 2018, Cap.590, s.2(2), p.3; BaFin, 2017). Although all firms that carrying on regulated activities in the UK are required to comply with the FSMA 2000, such as general prohibition and financial promotion (FCA, 2019b, pp.33-34), EEA firms may operate and promote their crypto-assets without authorisation in the UK under the general exclusion of the PERG (2019, section 2.9.15G).

Unregulated crypto-asset products and services provided by EEA firms either through the internet or in the UK can be mistakenly recognised as regulated tokens by uninformed consumers; associated market activities may mislead consumers, such as financial promotion. Authorities may consider a harmonised regulatory framework within the EEA regarding regulated token types and inform market participants, accordingly.

The second and third regulatory flaws in the UK may be patched after the EU withdrawal. Table 1 Disparate Regulation of Crypto-assets between the UK and EU 
$491 \quad$ insert table here\}

492 Table 2 Regulatory Flaws

493 \{insert table here\}

\section{Conclusions}

495 This paper diagnoses several issues in the current regulatory framework of crypto-assets in

496 the UK. These issues bring out the inconsistencies and ineffectiveness in crypto-assets

497 regulations including regulatory flaws. The current regulatory perimeters of the FCA

498 manifest a narrow scope applying to only the minority of crypto-asset products; the most

499 popular crypto-assets are currently unregulated. ${ }^{[6]}$ The complicated classification of crypto-

500 assets indirectly raises the administrative cost of firms and exposes consumers to risks.

501 The current classification of crypto-assets is inflexible. Given the rapid development of

502 financial technology, new varieties of crypto-assets may come into the markets. FinTech

503 firms have to adjust product lines and business models to catch up with the developments; the

504 UK authorities also need to adjust their regulatory scheme following markets variation,

505 accordingly. This situation incurs uncertainty in devising long-term regulation. Authorities

506 must take into account the dynamic connection between crypto-assets and the financial

507 markets and structure a simpler and more practical approach.

508 The analytical outcome brings to light three flaws in the current legal framework in the UK.

509 The three flaws exist in the secondary legislation, the RAO 2001 and the PERG 2019,

510 respectively, which are the core references of the crypto-asset regulation in the UK (FCA,

511 2019b). The flaw in Article 76 of the RAO 2001 will cause identification issues not only to

512 crypto-assets but to all 'specified investments' in the UK. The disparate regulatory

513 frameworks between the UK and EEA countries call out a harmonised regulatory scheme for 514 crypto-assets regardless of the EU withdrawal. 
515 In sum, the existing regulation on crypto-assets of the FCA is somewhat unclear,

516 incomprehensive and incomplete, and it is complicated and costly to firms. It may cripple the

517 enthusiasm for innovation and investments. Speculators may exploit regulatory

518 vulnerabilities and game the system, which exposes investors and consumers to risk. Such an

519 ineffective regulatory framework can impair market confidence and integrity. Despite money

520 laundering regulation, it is also crucial to establish a harmonised regulatory framework in the

521 EEA to overseeing overall internet-based business activities. The authority may have to

522 reassess the regulatory framework and consider appropriate adjustments.

523 This paper focuses solely on the effectiveness of the UK crypto-asset regulation; the

524 effectiveness of international collaboration also requires a thorough examination.

\section{Reference}

\section{Books}

527 Dean Armstrong QC, Dan Hyde and Sam Thomas. (2019), Blockchain and Cryptocurrency:

$528 \quad$ International Legal and Regulatory Challenges, Bloomsbury Professional.

529 Dryall, S. (2018), "Cryptocurrencies and Blockchain”, in Chishti, S. (Ed.), The WealthTech

$530 \quad$ Book, John Wiley \& Sons, pp. 158-161.

531 Magnuson, W. (2020) 'Crypto-Criminals', in Blockchain Democracy. Cambridge University Press, pp. 93-121.

533 Murray, A. (2019), Information Technology Law: The Law and Society, 4th ed., Oxford $534 \quad$ University Press.

\section{Cases}

536 “Citizen Service Berlin - Brandenburg - Criminality of trade in bitcoins”. (2019), available 537 at: http://www.gerichtsentscheidungen.berlin-

538 brandenburg.de/jportal/portal/t/279b/bs/10/page/sammlung.psml?pid=Dokumentanzei 539 ge\&showdoccase $=1 \& \mathrm{js} \_$peid $=$Trefferliste $\&$ documentnumber=1\&numberofresults $=1$ $540 \quad \&$ fromdoctodoc $=$ yes $\&$ doc.id=KORE223872018\&doc.part $=$ L\&doc.price $=0.0$ $541 \quad$ (accessed 8 December 2019). 
542 A\&M Records, Inc. v. Napster, Inc., 239 F.3d 1004 [9th Cir. 2001]

543 United States v Matthew Jones. [2014] No.6:14-mj-1233, So.1(M.D. Fla).

544 United States $v$ Shaun W. Bridges and Carl Mark Force IV. Defendants [2015] No.3-1554570370 Cal.Rptr.1 (N.D.Cal.).

\section{Journal Articles}

547 Albrecht, C. et al. (2019) 'The use of cryptocurrencies in the money laundering process', Journal of Money Laundering Control.

Arner, D. W., Barberis, J. and Buckley, R. P. (2017) 'FinTech, RegTech, and the Reconceptualization of Financial Regulation', Northwestern Journal of International Law \& Business, 3(3), pp. 371-414.

Brophy, R. (2019) 'Blockchain and insurance: a review for operations and regulation', Journal of Financial Regulation and Compliance, 28(2), pp. 215-234.

Brown, S.D. (2016), 'Cryptocurrency and criminality', The Police Journal: Theory, Practice and Principles, Vol. 89 No. 4, pp. 327-339.

Buocz, T., Ehrke-Rabel, T., Hödl, E. and Eisenberger, I. (2019), 'Bitcoin and the GDPR: Allocating responsibility in distributed networks', Computer Law and Security Review, pp.1-23.

Hughes, S. J. (2020) 'Do Blockchain Technologies Make Us Safer? Do Cryptocurrencies Necessarily Make Us Less Safe?', Texas International Law Journal, 55(3), pp. 373394.

Irwin, A. S. M. and Dawson, C. (2019) 'Following the cyber money trail: Global challenges when investigating ransomware attacks and how regulation can help', Journal of Money Laundering Control, 22(1).

Landes, W. and Lichtman, D. (2003), 'Indirect Liability for Copyright Infringement: Napster and Beyond', Journal of Economic Perspectives, Vol. 17 No. 2, pp.113-124.

Legrand, P. (1996), 'How to compare now', Legal Studies, Cambridge University Press, Vol. 56816 No. 2, pp. 232-242.

569 Li, Y., Susilo, W., Yang, G., Yu, Y., Du, X., Liu, D. and Guizani, N. (2019), 'Toward 570 Privacy and Regulation in Blockchain-Based Cryptocurrencies', IEEE Network, pp.1 571 $-7$. 
$572 \mathrm{Ng}, \mathrm{A} . \mathrm{W}$. and Kwok, B. K. B. (2017) 'Emergence of Fintech and cybersecurity in a global 573 financial centre: Strategic approach by a regulator', Journal of Financial Regulation and Compliance, 25(4), pp. 422-434.

Siems, M. and Deakin, S. (2010), 'Comparative Law and Finance: Past, Present, and Future Research', Journal of Institutional and Theoretical Economics, pp. 120-140.

Siems, M.M. (2008), 'Legal Originality', Oxford Journal of Legal Studies, Vol. 28 No. 1, pp.
Reyes, C. C. $(2017)$

Shih, R. and Ku, R. (2002), 'The Creative Destruction of Copyright: Napster and the New Economics of Digital', The University of Chicago Law Review, Vol. 69 No. 1, pp.263-324. $147-164$

Stern, R. (2000), 'Napster: A walking copyright infringement?', Micro Law, Vol. 95, pp.3-6.

Teichmann, F. M. J. (2018) 'Financing terrorism through cryptocurrencies - a danger for Europe?', Journal of Money Laundering Control.

Turner, A. and Irwin, A. S. (2018) 'Bitcoin transactions: a digital discovery of illicit activity on the blockchain', Journal of Financial Crime, 25(1), pp. 109-130.

Van Hoecke, M. (2016), 'Methodology of Comparative Legal Research', Law and Method, pp. 279-301.

Vovchenko, N. G. et al. (2017) 'Electronic currency: The potential risks to national security and methods to minimize them', European Research Studies Journal.

Walch, A. (2015), 'The Bitcoin Blockchain as financial market infrastructure: a consideration of operational risk', New York University Journal of Legislation \& Public Policy, Vol. 18.

595 Yeoh, P. (2017) 'Regulatory issues in blockchain technology', Journal of Financial 596 Regulation and Compliance, 25(2), pp. 196-208.

\section{$597 \quad$ Statutes}

598 “Banking Act (KWG)". (2014), Bundesgesetzblatt.

599 Act on the Prudential Supervision of Payment Services (Payment Services Supervision Act) 6002009.

601 Companies Act 2006 c.46.

602 Directive 2009/110/EC of the European Parliament and of the Council of 16 September 2009 603 on the taking up, pursuit and prudential supervision of the business of electronic 

money institutions amending Directives 2005/60/EC and 2006/48/EC and repealing

606 Directive 2000/46/EC, (2009) OJ L267/7.

607

Directive (EU) 2018/843 of the European Parliament and of the Council of 30 May 2018

607

608

609

610

611

612

613

614

615

616

617 Amending Directive (EU) 2015/849 on the Prevention of the Use of the Financial System for the Purposes of Money Laundering or Terrorist Financing, and Amending Directives 2009/138/EC and 2013/36/EU. (2018), OJ L156/43.

Directive (EU) 2015/2366 of the European Parliament and of the Council of 25 November 2015 on payment services in the internal market, amending Directives 2002/65/EC, 2009/110/EC and 2013/36/EU and Regulation (EU) No 1093/2010, and repealing Directive 2007/64/EC. (2015) OJ L337/35.

Directive 2014/65/EU of the European Parliament and of the Council of 15 May 2014 on Markets in Financial Instruments and Amending Directive 2002/92/EC and Directive 2011/61/EU. (2014), OJ L173/349.

618 Payment Services Regulations 2017, SI 2017/752.

619 The Financial Services and Markets Act 2000 (Carrying on Regulated Activities by Way of 620 Business) (Amendment) Order 2018, SI 2018/394.

621 The Financial Services and Markets Act 2000 (Regulated Activities) Order 2001, SI $622 \quad 2001 / 544$.

623 The Money Laundering and Terrorist Financing (Amendment) Regulations 2019, SI $624 \quad 2019 / 1511$.

625 The Virtual Financial Assets Act 2018, Cap.590.

\section{Working Papers}

627 Badev, A. and Chen, M. (2014), Bitcoin: Technical Background and Data Analysis, Finance 628 629 and Economics Discussion Series [No. 2014-104], Federal Reserve.

Baer, H. L. and Pavel, C. A. (1988), Does regulation drive innovation?, Federal Reserve 630 Bank of Chicago.

631 Blandin, A., et al. (2019), Global cryptoasset regulatory landscape study, Cambridge Centre 632 for Alternative Finance.

633 Blundell-Wignall, A. (2014), The Bitcoin Question: Currency versus Trust-Less Transfer 634 Technology, OECD Working Papers on Finance, Insurance and Private Pensions, Organisation for Economic Co-operation and Development. 
636 EBA. (2019), Report with Advice for the European Commission on Crypto-Assets.

637 FCA. (2017), Our Mission 2017: How we regulate financial services.

638 FCA. (2019a), CP19/3: Guidance on Cryptoassets UK.

639 FCA. (2019b), Guidance on Cryptoassets Feedback and Final Guidance to CP 19/3, Vol.

$640 \quad$ PS19/22.

641 FCA. (2019c), The Perimeter Guidance Manual.

642 FCA, (2020), Prohibiting the sale to retail clients of investment products that reference 643 cryptoassets.

644 HM Treasury, FCA and Bank of England. (2018), Cryptoassets Taskforce: Final Report.

645 Holloway, C. (2017), State of Illinois: Request for Information (RFI) Distributed Ledger and 646 Blockchain Applications in the Public Sector, State of Illinois.

647 Houben, R. and Snyers, A. (2018), Cryptocurrencies and Blockchain Legal Context and 648 Implications for Financial Crime, Money Laundering and Tax Evasion, European 649 Parliament's Special Committee on Financial Crimes, Tax Evasion and Tax $650 \quad$ Avoidance.

651 IMF. (2018), Private Crypto assets \& Central Bank Digital Currencies, International 652 Monetary Fund.

653 Nakamoto, S. (2008), Bitcoin: A Peer-to-Peer Electronic Cash System.

654 Norton Rose Fulbright 2015, Deciphering cryptocurrencies: A global legal and regulatory 655 guide, Norton Rose Fulbright, p.20.

656 The Law Library of Congress. (2018), Regulation of Cryptocurrency Around the World. 657 The World Bank. (2017), Distributed Ledger Technology (DLT) and Blockchain: FinTech $658 \quad$ Note 1.

659 Vandezande, N. and KU Leuven Centre for IT \& IP Law, (2018), Virtual Currencies : A $660 \quad$ Legal Framework, Intersentia.

\section{Websites}

662 BaFin. (2017), "Virtual Currency", available at:

663 https://www.bafin.de/EN/Aufsicht/FinTech/VirtualCurrency/virtual_currency_node_e 664 n.html (accessed 16 July 2019).

665 BBC News (2019) Hunting the missing millions from collapsed cryptocurrency. Available at: 666 https://www.bbc.co.uk/news/world-europe-50821547 (accessed: 23 August 2020). 
667 CoinMarketCap. (2020), “Today's Top 100 Crypto Coins Prices And Data”, available at: 668 https://coinmarketcap.com/coins/ (accessed 24 August 2020).

669 European Commission. (n.d.). "The European single market | Internal Market, Industry, 670 Entrepreneurship and SMEs", available at: https://ec.europa.eu/growth/singlemarket_en (accessed 5 November 2019).

Europol. (2019a), "Cryptocurrency laundering as a service: members of a criminal organisation arrested in Spain", available at: https://www.europol.europa.eu/newsroom/news/cryptocurrency-laundering-servicemembers-of-criminal-organisation-arrested-in-spain (accessed 15 June 2019).

Europol. (2019b), "Global Law Enforcement Action against Vendors and Buyers on the Dark Web", 26 March, available at: https://www.europol.europa.eu/newsroom/news/globallaw-enforcement-action-against-vendors-and-buyers-dark-web (accessed 10 November 2019).

FCA. (2017), "RegTech”, $F C A$, available at: https://www.fca.org.uk/firms/innovation/regtech (accessed 26 March 2020).

NDC-Department of Justice (2017) Russian National And Bitcoin Exchange Charged In 21Count Indictment For Operating Alleged International Money Laundering Scheme And Allegedly Laundering Funds From Hack Of Mt. Gox, Northern District of California Department of Justice. available at: https://www.justice.gov/usaondca/pr/russian-national-and-bitcoin-exchange-charged-21-count-indictmentoperating-alleged (accessed: 23 August 2020).

The Law Library of Congress. (2018), "Germany: Court Holds That Bitcoin Trading Does Not Require a Banking License", available at: https://www.loc.gov/law/foreignnews/article/germany-court-holds-that-bitcoin-trading-does-not-require-a-bankinglicense/ (accessed 8 December 2019).

\footnotetext{
${ }^{[1]}$ According to CoinMarketCap $<$ https://coinmarketcap.com> accessed 03 June 2020.

${ }^{[2]}$ According to Coin.market < https://coin.market/exchanges $>$ accessed 03 June 2020.

${ }^{[3]}$ There were over 2,300 crypto-assets in July 2019. $<$ https://coinmarketcap.com $>$ accessed 02 July 2019.
}

${ }^{[4]}$ The term of transferable in this definition does not refer to money transactions and remittance among individuals, which separates the security tokens from e-money tokens and exchange tokens.

[5] The court judgement is in German; thus, the information is based on Google translation. 
[6] Unregulated tokens in the UK shall comply with the Money Laundering Regulation 2019, which implements the EU Fifth Anti-Money Laundering Regulation Directive. However, anti-money laundering is not the research objective of this paper. 
Table 1 Disparate Regulation of crypto assets between the UK and EU

\begin{tabular}{lll}
\hline \multicolumn{1}{c}{ Crypto Assets } & $\begin{array}{c}\text { Require Authorisation of the FCA (FCA, } \\
\text { 2019b) }\end{array}$ & \multicolumn{1}{c}{ EU Regulation (EBA, 2019) } \\
\hline Security tokens & $\begin{array}{l}\text { Regulated under the MiFID II for financial } \\
\text { instruments or the RAO 2001 for specified } \\
\text { investments }\end{array}$ & $\begin{array}{l}\text { Refer to investment tokens in the EU. Include 'ownership rights } \\
\text { and/or entitlements similar to dividends', for example, ICOs. } \\
\text { (EBA, 2019, p.7). }\end{array}$ \\
\hline E-money tokens & $\begin{array}{l}\text { Refer to virtual currencies in the EU including exchange and } \\
\text { payment tokens (EBA, 2019, pp.6-7). 'Current EU law does not } \\
\text { prohibit financial institutions, including credit institutions, } \\
\text { investment firms, payment institutions and electronic money } \\
\text { institutions, from holding or gaining exposure to crypto-assets or } \\
\text { from offering services relating to crypto-assets. (These types of } \\
\text { firm are permitted, pursuant to their licence status, to carry out } \\
\text { specified regulated financial services listed in the relevant } \\
\text { directive' (EBA, 2019, p.22). Firms meet certain criteria are } \\
\text { regulated under the Electronic Money Directive (Council } \\
\text { PSR 2017 }\end{array}$ & $\begin{array}{l}\text { Directive 2009/110/EC, 2009) for e-money tokens, the Payment } \\
\text { pervices Directive (Council Directive (EU) 2015/2366, 2015) for } \\
\text { payment instruments and the MiFID II for financial instruments } \\
\text { (EBA, 2019, pp.7, 12 and 29), accordingly. }\end{array}$ \\
\hline Exchange tokens & Do not require the authorisation of the FCA and the & Under observation (EBA, 2019, p.28) \\
\hline Utility tokens & Do not require the authorisation of the FCA & \\
\hline
\end{tabular}

1. Crypto assets classification in the UK and EU is disparate.

2. Crypto assets regulated in the EU are not necessarily regulated in the UK and vice versa. 
Table 2 Regulatory Flaws

\begin{tabular}{|c|c|c|}
\hline Related Laws and Regulations & Identified Issues & Regulatory Flaws \\
\hline RAO 2001, Article 76 & Mutually exclusive phrases in the Article & $\begin{array}{l}\text { The share-type tokens of industrial and provident } \\
\text { societies or credit unions, or in a body constituted } \\
\text { under the law of another EEA State can be } \\
\text { apprehended as both regulated and unregulated } \\
\text { crypto-assets at the same time. } \\
\text { Further clarification will help market participants } \\
\text { to comply with the law. }\end{array}$ \\
\hline \multirow[t]{2}{*}{$\begin{array}{l}\text { PEGR 2019, Section 2.9.15G } \\
\text { EU Single Market System }\end{array}$} & Exception of authorisation for EEA e-commerce & $\begin{array}{l}\text { EEA authorised tokens may not be regulated in } \\
\text { the UK, however, can operate in the UK through } \\
\text { the internet. This flaw can be patched after EU } \\
\text { withdrawal. }\end{array}$ \\
\hline & $\begin{array}{l}\text { Disparate regulation of crypto-assets between EEA and the } \\
\text { UK (see table 1) }\end{array}$ & $\begin{array}{l}\text { EEA authorised tokens may not be regulated in } \\
\text { the UK. However, promoting a token using an } \\
\text { EEA licence may confuse UK consumers. This } \\
\text { flaw can be patched after EU withdrawal. }\end{array}$ \\
\hline
\end{tabular}

